\title{
Partisipasi Kelompok Kerja Guru Pendidikan Agama Islam Sekolah Dasar (KKG PAI SD) Kabupaten Boyolali dalam Meningkatkan Kompetensi Guru PAI SD
}

\author{
Fauzi Muharom \\ IAIN Surakarta \\ fauzimuharom@yahoo.com
}

\begin{abstract}
This study aims to know the participation of Teachers Working Group (KKG) and mapping the needs of improving the competence of teachers PAI elementary school in Boyolali district. This type of research is a qualitative descriptive with analytical interactive method. The results showed that PAI KKG SD Participation Boyolali district in improving competence PAI elementary teachers include; Training Lesson Study, training 2013 curriculum, PAI teacher development program and assist in the teacher's administration. While the results of the mapping of needs to increase the competence of teachers PAI elementary school in Boyolal, include: training curriculum 2013, PTK, BTA and learning media.

Keywords: Participation, Teachers Competency PAI, PAI Elementary Teacher Working Group (KKG PAI SD)
\end{abstract}

\begin{abstract}
Abstrak
Penelitian ini bertujuan untuk mengetahui partisipasi Kelompok Kerja Guru (KKG) dan pemetaan kebutuhan peningkatan kompetensi Guru PAI SD di kabupaten Boyolali. Jenis penelitian ini adalah kualitatif deskriptif dengan metode analitis-interaktif. Hasil penelitian menunjukkan bahwa Partisipasi KKG PAI SD kabupaten Boyolali dalam meningkatkan kompetensi guru PAI SD meliputi; Pelatihan Lesson Study, Bintek/pelatihan Kurikulum 2013, Program pengembangan guru PAI dan membantu administrasi keguruan. Sedangkan hasil pemetaan kebutuhan peningkatan kompetensi guru PAI SD di Kabupaten Boyolali meliputi: pelatihan kurikulum 2013, pelatihan PTK, pelatihan BTA dan pelatihan media pembelajaran.
\end{abstract}

Kata Kunci: Partisipasi; Kompetensi Guru PAI; Kelompok Kerja Guru PAI SD; Boyolali 


\section{Pendahuluan}

Tidak dapat dipungkiri bahwa tugas dan tanggung jawab guru saat ini sangat besar dalam dunia pendidikan. Tugas dan tanggung jawab guru antara lain guru sebagai pengajar, sebagai pembimbing, dan sebagai administrator. ${ }^{1}$ Di mana sebagai pengajar guru lebih menekankan kepada tugas dalam merencanakan dan melaksanakan pengajaran. Sebagai pembimbing, berarti guru memberi tugas dan memberikan bantuan kepada siswa dalam pemecahan masalah yang dihadapinya. Sedangkan guru sebagai administrator kelas pada hakikatnya merupakan jalinan antara pengajaran dan ketatalaksanaan pada umumnya.

Guru sebagai komponen utama dalam dunia pendidikan dituntut untuk mampu mengimbangi bahkan melampaui perkembangan ilmu pengetahuan dan teknologi yang berkembang dalam masyarakat. Tuntutan ini sesuai dengan Standar Nasional Pendidikan bahwa pendidik harus memiliki kualifikasi akademik dan kompetensi sebagai agen pembelajaran, sehat jasmani dan rohani, serta memiliki kemampuan untuk mewujudkan tujuan pendidikan nasional.

Sebagai agen pembelajaran (learning agent) dalam proses pendidikan, salah satu peran guru adalah sebagai pemberi inspirasi belajar bagi peserta didik, sehingga kegiatan belajar dan pembelajaran dapat membangkitkan berbagai pemikiran, gagasan, dan ide-ide baru. Untuk kepentingan tersebut, guru harus mampu menciptakan lingkungan sekolah yang aman, nyaman dan tertib, optimisme dan harapan yang tinggi dari seluruh warga sekolah, kesehatan sekolah, serta kegiatan-kegiatan yang terpusat pada peserta didik (student centered activities ), agar dapat memberikan inspirasi, membangkitkan nafsu, gairah dan semangat belajar. ${ }^{2}$

Menjadi guru inspiratif bukanlah sekedar guru kurikulum, tapi mampu mengembangkan potensi dan kemampuan siswa, berpikir kreatif dan mampu melahirkan siswa yang tangguh dan

${ }^{1}$ Nana Sudjana, Dasar-dasar Proses Belajar Mengajar (Bandung: Sinar Baru, 1991), hlm. 15.

${ }^{2}$ Mulyasa, Standar Kompetensi dan Sertifikasi Guru (Bandung: Remaja Rosdakarya, 2013), hlm. 67. 
siap menghadapi aneka tantangan dan perubahan. ${ }^{3}$ Guru yang inspiratif akan bertindak di luar ketentuan formal, melampaui batas kurikulum dan senantiasa berusaha mengembangkan potensi, wawasan, cara pandang serta orientasi siswa.

Guru inspiratif idealnya dimiliki oleh semua guru, termasuk di dalamnya guru PAI. Mereka tidak hanya memberikan pembelajaran agama secara konvensional yang hanya mengasah ranah kognitif dan terpaku pada dokumen kurikulum formal. Akan tetapi mereka harus mengemas materi yang aktual dan kontekstual, pembelajaran aktif, dan evaluasi pembelajaran yang komprehensif, mencakup ranah kognitif, afektif dan psikomotorik. Hal ini berarti guru PAI perlu memiliki kompetensi lengkap, yakni kompetensi pedagogik, kepribadian, sosial, dan professional sesuai yang diamanatkan dalam UU No. 20 tahun 2003, UU No. 14 tahun 2005, dan PP No. 74 tahun 2008. ${ }^{4}$

Keinginan pemerintah agar setiap guru memiliki kompetensi ini harus didukung oleh para guru itu sendiri ataupun oleh kelompok guru. Khusus untuk kelompok guru sangat dekat dengan peningkatan kompetensi guru, karena kelompok guru adalah kelompok kerja dari guru-guru yang berorientasi kepada peningkatan kualitas pengetahuan, penguasaan materi, teknik mengajar, interaksi guru murid, metode mengajar, dan lain lain yang berfokus pada penciptaan kegiatan belajar mengajar yang aktif. Salah satu kelompok guru yang eksis di antara kelompok guru di Indonesia adalah KKG. KKG merupakan wadah atau forum kegiatan profesional bagi para guru di tingkat gugus atau kecamatan yang terdiri dari beberapa guru dari beberapa sekolah.

Salah satu KKG yang melakukan kegiatan dalam peningkatan kompetensi guru adalah KKG PAI SD Kabupaten Boyolali. KKG PAI SD Kabupaten Boyolali mempunyai area yang luas yakni meliputi 19 kecamatan, sehingga memiliki 19 KKG PAI SD tingkat kecamatan. ${ }^{5}$ Berdasarkan realita inilah muncul

${ }^{3}$ Ngainun Na`im, Menjadi Guru Inspiratif: Memberdayakan dan Mengubah Jalan Hidup Siswa (Yogyakarta: Pustaka Pelajar, 2009), hlm. 73.

${ }^{4}$ UU No. 20 tahun 2003 tentang Sistem Pendidikan Nasional; UU No. 14 tahun 2005 tentang Guru dan Dosen, dan PP No. 74 tahun 2008 tentang Guru.

${ }^{5}$ Hasil wawancara awal dengan Bapak Samidi, selaku ketua KKG PAI SD Kabupaten Boyolali pada tanggal 26 Maret 2016. 
kegelisahan akademik untuk melakukan ekplorasi lebih lanjut yang berkaitan dengan peranan atau partisipasi KKG PAI SD dalam peningkatan kompetensi guru PAI SD di Kabupaten Boyolali. Di samping itu akan dilakukan pemetaan terhadap kebutuhan peningkatan kompetensi guru PAI SD di Kabupaten Boyolali.

\section{Kelompok Kerja Guru}

Kelompok Kerja Guru (KKG) dapat diartikan sebagai wadah profesional guru yang aktif, kompak dan akrab yang membahas permasalahan dari mereka dan untuk mereka. Dalam PMA No. 16 Tahun 2010 pasal 1, ayat 11 dinyatakan bahwa Kelompok Kerja Guru Pendidikan Agama adalah organisasi pembinaan profesi Guru Pendidikan Agama pada SD dan SDLB.

Berdasarkan pengertian di atas maka eksistensi Kelompok Kerja Guru memiliki peran yang sangat sentral dan strategis dalam pemberdayaan dan peningkatan kompetensi Guru. KKG merupakan salah satu Organisasi profesi guru yang berfungsi untuk memajukan profesi, meningkatkan kompetensi, karier, wawasan kependidikan, perlindungan profesi, kesejahteraan, dan pengabdian kepada masyarakat. ${ }^{7}$ Tugas dan fungsi dari Kelompok Kerja Guru adalah melakukan peningkatan kemampuan guru sebagai tenaga kependidikan yang berhubungan dengan silabus, Rencana Pelaksanaan Pembelajaran (RPP), pengembangan bahan ajar, pendayagunaan media dan sumber belajar, penilaian, pelaksanaan bimbingan serta diskusi mencari alternatif penyelesaian berbagai masalah dan penetapan kegiatan. ${ }^{8}$

\section{Kompetensi Guru PAI}

Pengertian kompetensi berasal dari bahasa Inggris “competence', yang artinya kecakapan atau kemampuan. ${ }^{9}$ Kompetensi berarti suatu hal yang menggambarkan

${ }^{6}$ Din Wahyudin, Monitoring dan Evaluasi Petunjuk bagi Para Pelaksana (Jakarta: PEQIP, 1995), hlm. 10.

${ }^{7}$ UU No. 14 tahun 2015 pasal 41.

${ }^{8}$ Mulyasa, Uji Kompetensi dan Penilaian Kinerja Guru (Bandung : PT Remaja Rosdakarya, 2013), hlm. 143.

${ }^{9}$ John M. Echols, Hassan Shadily, Kamus Inggris-Indonesia (Jakarta:, PT. Gramedia Pustaka Utama, 1996), hlm. 132. 
kualifikasi atau kemampuan seseorang baik kuantitatif maupun kualitatif. ${ }^{10}$ Dihubungkan dengan guru, maka kompetensi dalam hal ini adalah kemampuan dan kewenangan guru dalam melaksanakan profesi keguruannya. ${ }^{11}$ Beberapa kompetensi guru agama adalah menguasai substansi materi pelajaran, menguasai metodologi mengajar, menguasai teknik evaluasi dengan baik dan memahami, menghayati, dan mengamalkan nilai-nilai moral dan kode etik profesi. ${ }^{12}$

Pemerintah sangat konsen dalam masalah kompetensi guru ini dan sebagai buktinya menerbitkan PP No. 74 tahun $2008 .^{13}$ Kompetensi guru dalam hal ini meliputi kompetensi pedagogik, kompetensi kepribadian, kompetensi sosial, dan kompetensi professional.

Keempat kompetensi guru tersebut secara teoritis dapat dipisahkan satu dengan lainnya, namun dalam praktiknya keempat kompetensi tersebut harus teraplikasikan secara simultan dan bersama-sama. Guru yang memiliki kompetensi pedagogik dan profesional harus dibarengi memiliki kompetensi kepribadian dan sosial. Keempat kompetensi tersebut terpadu dalam karakteristik tingkah laku guru. ${ }^{14}$ Apalagi guru tersebut adalah guru Agama Islam, maka keempat kompetensi tersebut harus berjalan secara bersama. Karena dalam persepektif pendidikan Islam, guru dapat diposisikan sebagai orang yang 'alim dan sebagai uswah sehingga guru dituntut juga beramal shaleh sebagai aktualisasi dari keilmuan yang dimilikinya. Sebagai guru, ia juga bertanggung jawab kepada siswanya, tidak saja ketika proses pembelajaran berakhir, bahkan sampai di

${ }^{10}$ Moh. Uzer Usman, Menjadi Guru Profesional ( Bandung: PT. Remaja Rosdakarya, 2001), hlm. 4.

${ }^{11}$ Akmal Hawi, Kompetensi Guru Pendidikan Agama Islam (Jakarta: PT Grafindo Persada, 2013), hlm. 4.

${ }^{12}$ Ramayulis, Metodologi Pendidikan Agama Islam (Jakarta: Kalam Mulia, 2005), hlm. 60.

${ }^{13}$ Peraturan Pemerintah No. 74 Tahun 2008 sebagai tindak lanjut dari Undang-Undang Nomor 14 Tahun 2005 tentang Guru dan Dosen. Lihat juga dalam Jejen Musfah. Peningkatan Kompetensi Guru Melalui Pelatihan Sumber Belajar Teori dan Praktik (Jakarta: Kencana Prenada Media Group,2012), hlm. 30.

${ }^{14}$ Harsono \& MJ Susilo. Pemberontakan Guru: Menuju Peningkatan Kualitas (Yogyakarta: Pustaka Pelajar, 2010), hlm. 30-31. 
akhirat. Oleh karena itu, wajar jika mereka diposisikan sebagai orang-orang penting dan mempunyai pengaruh besar pada masanya, dan seolah-olah memegang kunci keselamatan rohani dalam masyarakat. ${ }^{15}$

\section{Metode Penelitian}

Penelitian ini akan melakukan kajian terhadap partisipasi KKG dalam meningkatkan kompetensi Guru PAI SD dan pemetaan kebutuhan peningkatan kompetensi guru PAI SD di Kabupaten Boyolali. Sehingga nampaklah bahwa penelitian ini merupakan penelitian kualitatif dan bersifat deskriptif analitis. ${ }^{16}$

Metode yang digunakan untuk mengumpulkan data dalam penelitian ini adalah wawancara, dokumentasi dan FGD. Wawancara lebih fokus kepada ketua dan pengurus KKG PAI SD Kabupaten Boyolali maupun ketua dan pengurus KKG PAI SD kecamatan di Kabupaten Boyolali. Untuk metode dokumentasi digunakan untuk mengumpulkan dokumen profil KKG PAI SD Kabupaten Boyolali ataupun KKG PAI SD kecamatan. Sedangkan Teknik FGD ini dilakukan dengan mengumpulkan para pengurus KKG PAI SD Kabupaten Boyolali dan dikombinasi dengan para pengurus KKG PAI SD kecamatan di Kabupaten Boyolali. FGD ini lebih digunakan untuk pencarian data tentang kegiatan-kegiatan yang sudah dan yang belum dilakukan oleh KKG PAI SD Kabupaten Boyolali dalam hubungannya dengan peningkatan kompetensi Guru PAI SD.

Setelah data-data penelitian ini terkumpul maka selanjutnya dianalisis dengan model interaktif (interactive model of analysis). Artinya, ketiga komponen dalam kegiatan penelitian yakni data reduction (reduksi data), data display (penyajian data) dan conclusions drawing and verifying (penarikan kesimpulan dan verifikasi) dilakukan secara bersama-sama dan saling berkaitan. ${ }^{17}$

${ }^{15}$ Ngainun Naim, Menjadi........hlm. 5.

${ }^{16}$ Lexy. J. Moleong, Metodologi Penelitian Kualitatif (Bandung: Remaja Rosdakarya, 2002), hlm. 125-133.

${ }^{17}$ Reduksi data, merupakan proses seleksi, pemfokusan, penyederhanaan dan abstraksi data kasar yang berdasarkan dari catatan-catatan tertulis di lapangan (fieldnote). Penyajian data, setelah data direduksi langkah selanjutnya adalah memilah-milah data sesuai dengan pengelompokkan yang telah ditentukan dengan membuat semacam matriks, skema atau tabel. Hal ini 


\section{Analisis Partisipasi KKG PAI SD Kabupaten Boyolali da- lam Meningkatkan Kompetensi Guru PAI SD}

Berdasarkan hasil wawancara, dokumentasi dan FGD yang telah dilakukan, maka partisipasi KKG PAI SD Kabupaten Boyolali dalam meningkatkan kompetensi guru PAI SD adalah:

1. Pengadaan Pelatihan Lesson Study

Menurut ketua KKG PAI SD Kabupaten Boyolali, kegiatan pelatihan ini penting dilaksanakan karena Lesson Study merupakan kegiatan yang mengedepankan kompetensi pedagogik sekaligus kompetensi sosial dari para guru. Di sini para guru dikondisikan untuk memperbaiki dan mengembangkan proses pembelajaran agar lebih baik secara sistematis, kolaboratif, berkelompok, dan berkesinambungan. Manfaat yang dapat diambil dari proses ini adalah seorang guru dapat menimba pengetahuan dari guru lainnya, sehingga terjadi proses sharing akademik ataupun sharing pengalaman antar guru.

Dalam pelatihan ini tiap KKG PAI SD kecamatan mengirimkan delegasinya. Pelatihan ini didesain selama dua hari dan hari terakhir diadakan simulasi atau praktik di kelas dengan menggunakan langkah-langkah dalam lesson study yakni:

a. Plan (perencanaan pembelajaran)

b. Do (pelaksanaan dan pengamatan pembelajaran)

c. See (refleksi dari pembelajaran)

2. Pengadaan Bintek Kurikulum 2013

Pilot project pelaksanaan Kurikulum 2013 di Kabupaten Boyolali adalah SDN 1 Klewor, SDN 1 Kemusu, SDN Simo 1, SDN Sambi 1, SDN Ngaru-ngaru 2 Banyudono, SDN 9 Boyolali. Dalam pelaksanaan Kurikulum 2013 ini ditemukan masalah-masalah di lapangan seperti kesulitan guru dalam penerapan scientific approach, kesulitan guru dalam membuat siswa aktif, kesulitan guru dalam penilaian otentik, dan lain-lain. Berdasarkan hal ini pelatihan tentang

memudahkan dalam pemahaman. Kesimpulan, dalam hal ini peneliti berusaha untuk menarik kesimpulan berdasarkan semua hal dari reduksi data dan penyajian data. Lihat Matthew B. Miles and A. Michael Huberman, Analisis Data Kualitatif, Terj. Tjetjep Rohandi Raihidi (Jakarta: UI Press, 1992), hlm. 59-60. 
implementasi Kurikulum 2013 perlu dilakukan di kalangan guru-guru PAI SD di Kabupaten Boyolali. Bintek Kurikulum 2013 ini dilakukan bekerjasama dengan Seksi Pendidikan Agama dan keagamaan Islam (PAKIS) Kantor Kementerian Agama (Kemenag) Kabupaten Boyolali.

3. Pengadaan Program pengembangan diri PAI

Pengembangan diri PAI ini sebenarnya dilaksanakan untuk mendukung kegiatan belajar di dalam kelas. KKG PAI SD Kabupaten Boyolali memandang perlu adanya program pengembangan diri PAI dengan mengumpulkan seluruh guru PAI SD di Kabupaten Boyolali. Tujuannya adalah menyamakan persepsi untuk implementasi pengembangan diri siswa yang dipandu oleh guru. Sehingga guru bisa bertambah dan meningkat dalam kompetensinya.

Kegiatan ini melibatkan seluruh guru PAI SD di Kabupaten Boyolali, sehingga program ini diadakan dengan 3 gelombang dan tiap gelombang mencapai 150 peserta. Program pengembangan diri PAI ini meliputi 3 unsur yakni:

a. Kegiatan Ekstra Kurikuler

b. Pembiasaan akhlak mulia

c. Kegiatan Bimbingan siswa seperti membimbing anak yang akan maju lomba, membimbing anak yang belum bisa BTA, membimbing anak yang shalatnya yg belum bisa, dan lain-lain

Kegiatan-kegiatan lain yang menjadi garapan dari KKG PAI SD di Kabupaten Boyolali dalam hubungannya dengan kepentingan guru adalah pembuatan adminstrasi GPAI seperti Silabus, Prota, Promes, RPP, Daftar hadir siswa, Form penilaian siswa dan lain-lain. Bahkan KKG PAI SD di Kabupaten Boyolali juga mengurusi nasib guru PAI dalam hubungannya dengan tunjangan sertifikasi, yakni pendampingan secara tuntas pemberkasan sertifikasi guru sampai pencairannya.

\section{Pemetaan Kebutuhan Peningkatan Kompetensi Guru PAI SD Di Kabupaten Boyolali}

Pemetaan tentang kebutuhan peningkatan kompetensi Guru PAI SD di 19 kecamatan di Kabupaten Boyolali dapat diuraikan seperti data di bawah ini: 
1. Pemetaan Kebutuhan Peningkatan Kompetensi GPAI SD di Kecamatan Wonosegara, yaitu:

a. Pelatihan Kurikulum 2013

b. Pelatihan media

c. Pelatihan PTK

2. Pemetaan Kebutuhan Peningkatan Kompetensi GPAI SD di Kecamatan Teras, yaitu:

a. Pelatihan BTA

b. Pelatihan murotal

3. Pemetaan Kebutuhan Peningkatan Kompetensi GPAI SD di Kecamatan Simo, yaitu: Pelatihan BTA

4. Pemetaan Kebutuhan Peningkatan Kompetensi GPAI SD di Kecamatan Selo, yaitu:

a. Pelatihan tilawah

b. Pelatihan Kurikulum 2013

5. Pemetaan Kebutuhan Peningkatan Kompetensi GPAI SD di Kecamatan Sawit, yaitu:

a. Pelatihan Kurikulum 2013

b. Pelatihan tilawah

6. Pemetaan Kebutuhan Peningkatan Kompetensi GPAI SD di Kecamatan Nogosari, yaitu:

a. Pelatihan tilawah

b. Pelatihan PTK

7. Pemetaan Kebutuhan Peningkatan Kompetensi GPAI SD di Kecamatan Ngemplak, yaitu:

a. Pelatihan media alat peraga

b. Pelatihan BTA

8. Pemetaan Kebutuhan Peningkatan Kompetensi GPAI SD di Kecamatan Klego, yaitu:

a. Pelatihan media

b. Pelatihan PTK

9. Pemetaan Kebutuhan Peningkatan Kompetensi GPAI SD di Kecamatan Karanggedhe, yaitu:

a. Pelatihan Kurikulum 2013

b. Pelatihan BTA

c. Pelatihan tilawah

10. Pemetaan Kebutuhan Peningkatan Kompetensi GPAI SD di Kecamatan Juwangi, yaitu:

a. Pelatihan Kurikulum 2013

b. Pelatihan tilawah 
11. Pemetaan Kebutuhan Peningkatan Kompetensi GPAI SD di Kecamatan Banyudono, yaitu:

a. Pelatihan media pembelajaran

b. Pelatihan Kurikulum 2013

c. Pelatihan tilawah

12. Pemetaan Kebutuhan Peningkatan Kompetensi GPAI SD di Kecamatan Andong, yaitu:

a. Pelatihan Kurikulum 2013

b. Pelatihan tilawah

13. Pemetaan Kebutuhan Peningkatan Kompetensi GPAI SD di Kecamatan Cepogo, yaitu:
a. Pelatihan tilawah
b. Pelatihan murotal

14. Pemetaan Kebutuhan Peningkatan Kompetensi GPAI SD di Kecamatan Mojosongo, yaitu:
a. Pelatihan media pembelajaran
b. Pelatihan murotal
c. Pelatihan tilawah

15. Pemetaan Kebutuhan Peningkatan Kompetensi GPAI SD di Kecamatan Boyolali, yaitu:

a. Pelatihan media pembelajaran berbasis IT

b. Pelatihan BTA

16. Pemetaan Kebutuhan Peningkatan Kompetensi GPAI SD di Kecamatan Ampel, yaitu:

a. Pelatihan tilawah

b. Pelatihan murotal

17. Pemetaan Kebutuhan Peningkatan Kompetensi GPAI SD di Kecamatan Kemusu, yaitu:
a. Pelatihan media pembelajaran berbasis IT
b. Pelatihan tilawah
c. Pelatihan murotal

18. Pemetaan Kebutuhan Peningkatan Kompetensi GPAI SD di Kecamatan Musuk, yaitu: Pelatihan BTA

19. Pemetaan Kebutuhan Peningkatan Kompetensi GPAI SD di Kecamatan Sambi, yaitu:

a. Pelatihan tilawah

b. Pelatihan murotal 
Berdasarkan pemetaan kebutuhan peningkatan kompetensi Guru PAI SD di 19 kecamatan di Kabupaten Boyolali di atas maka dapat dikelompokkan sebagai berikut:

Tabel 1.

Pemetaan Kebutuhan Peningkatan Kompetensi Guru

PAI SD

di Kabupaten Boyolali

\begin{tabular}{lll}
\hline No Jenis Kebutuhan & Nama KKG \\
\hline PAI SD
\end{tabular}




Simo
Selo
Sawit
Nogosari
Ngemplak
Karangedhe
Juwangi
Banyudono
Andong
Cepogo
Mojosongo
Boyolali
Ampel
Kemusu
Musuk
Sambi

\section{Kesimpulan}

Berdasarkan uraian-uraian di atas, maka dapatlah diambil beberapa kesimpulan yaitu:

1. Partisipasi KKG PAI SD kabupaten boyolali dalam meningkatkan kompetensi guru PAI SD yaitu:

a. Pengadaan Pelatihan Lesson Study

Dalam pelatihan ini tiap KKG PAI SD Kecamatan mengirimkan delegasinya. Pelatihan ini didesain selama dua hari dan hari terakhir diadakan simulasi atau praktik di kelas dengan menggunakan langkah-langkah dalam lesson study yakni plan, do, see.

b. Pengadaan Bintek Kurikulum 2013

Bintek Kurikulum 2013 ini dilakukan bekerjasama dengan Seksi Pendidikan Agama dan keagamaan Islam (PAKIS) Kantor Kementerian Agama (Kemenag) Kabupaten Boyolali.

c. Pengadaan Program pengembangan diri PAI

Kegiatan ini melibatkan seluruh guru PAI SD di Kabupaten Boyolali, sehingga program ini diadakan dengan 3 gelombang dan tiap gelombang mencapai 150 peserta. 
Program pengembangan diri PAI ini meliputi 3 unsur yakni kegiatan ekstra kurikuler, pembiasaan akhlak mulia, kegiatan bimbingan siswa seperti membimbing anak yang akan maju lomba, membimbing anak yang belum bisa BTA, membimbing anak yang shalatnya yg belum bisa, dan lain-lain.

2. Hasil pemetaan kebutuhan peningkatan kompetensi guru PAI SD di Kabupaten Boyolali yang disampaikan oleh pengurus KKG PAI SD di sembilas belas kecamatan yakni pelatihan kurikulum 2013, pelatihan PTK, pelatihan BTA, pelatihan murotal, pelatihan tilawah, dan pelatihan media pembelajaran.

\section{Daftar Pustaka}

Echols, John M., Hassan Shadily, 1996. Kamus InggrisIndonesia. Jakarta:, PT. Gramedia Pustaka Utama.

Daulay, Haidar Putra, 2004. Pendidikan Islam dalam Sistem Pendidikan Nasional di Indonesia. Jakarta: Prenada Media.

Harsono dan MJ Susilo, 2010. Pemberontakan Guru: Menuju Peningkatan Kualitas. Yogyakarta: Pustaka Pelajar.

Hawi, Akmal, 2013. Kompetensi Guru Pendidikan Agama Islam. Jakarta: PT Grafindo Persada.

Miles, Matthew B. and A. Michael Huberman, 1992. Analisis Data Kualitatif, Terj. Tjetjep Rohandi Raihidi. Jakarta: UI Press.

Moleong, Lexy. J., 2002. Metodologi Penelitian Kualitatif. Bandung: Remaja Rosdakarya.

Mulyasa, 2013. Uji Kompetensi dan Penilaian Kinerja Guru. Bandung: PT Remaja Rosdakarya. 2013. Standar Kompetensi dan Sertifikasi Guru. Bandung: PT. Remaja Rosdakarya.

Munib, Achmad, 2009. Pengantar Ilmu Pendidikan. Semarang: UNNES Press.

Musfah, Jejen, 2012. Peningkatan Kompetensi Guru Melalui Pelatihan Sumber Belajar Teori dan Praktik. Jakarta: Kencana Prenada Media Group.

Na'im, Ngainun, 2009. Menjadi Guru Inspiratif: Memberdayakan dan Mengubah Jalan Hidup Siswa. Yogyakarta: Pustaka Pelajar.. 
Sudjana, Nana, 1991. Dasar-dasar Proses Belajar Mengajar. Bandung: Sinar Baru.

Tirtarahardja dan La Sulo, 2005. Pengantar pendidikan. Jakarta: Rineka Cipta.

Usman, Moh. Uzer, 2001. Menjadi Guru Profesional. Bandung: PT. Remaja Rosdakarya.

Wahyudin, Din, 1995. Monitoring dan Evaluasi Petunjuk bagi Para Pelaksana. Jakarta: PEQIP. 